\title{
Isotherm and Thermodynamic Studies on the Bio Adsorption of Textile Industrial Effluents onto Chitosan Nanoparticle from Macolor Niger (White Snapper)
}

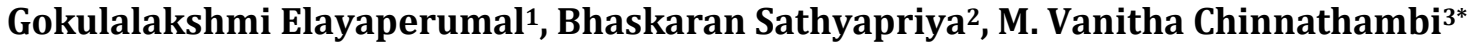 \\ ${ }^{1}$ Human Genetics Laboratory, Sree Balaji Dental College and Hospital, Bharath Institute of Higher Education and Research, \\ Chennai, Tamilnadu, India \\ ${ }^{2}$ Department of Anatomy, Sree Balaji Dental College and Hospital, Bharath Institute of Higher Education and Research, Chennai, \\ Tamilnadu, India \\ ${ }^{3}$ Department of Biotechnology, Guru Nanak College Chennai, Tamilnadu, India \\ Email: *dr.sathyapriyalakshmanan@yahoo.com
}

How to cite this paper: Elayaperumal, G., Sathyapriya, B. and Chinnathambi, M.V. (2019) Isotherm and Thermodynamic Studies on the Bio Adsorption of Textile Industrial Effluents onto Chitosan Nanoparticle from Macolor Niger (White Snapper). Journal of Biomaterials and Nanobiotechnology, 10, 1-10.

https://doi.org/10.4236/jbnb.2019.101001

Received: July 18, 2018

Accepted: January 6, 2019

Published: January 9, 2019

Copyright $\odot 2019$ by author(s) and Scientific Research Publishing Inc. This work is licensed under the Creative Commons Attribution International License (CC BY 4.0).

http://creativecommons.org/licenses/by/4.0/

(c) (i) Open Access

\begin{abstract}
Fish scale wastes are generally discarded in the environment through fish processing industries and local market vendors. It is one of the excellent and efficient renewable bioproducts. Consequently, a number of bioactive compounds have been identified including bioactive peptides, collagen, chitosan, and gelatin which are commercially marketed. The current study involves the extraction and generation of chitosan nanoparticles from fish scales. The synthesized chitosan nanosubstances were categorized by Field Emission Scanning Electron Microscopy (FESEM). The viability of utilizing fish scales as an economical bio-adsorbent for elimination of textile dye was studied on industrial effluent. Fourier transform infrared spectroscopy (FTIR) was used to study the dye adsorption of chitosan nanoparticles before and after the dye treatment. With chitosan nanoparticle treatment of the textile effluents, removal of COD was improved to $80 \%$ and the turbidity removal efficiency was improved up to $90 \%$. Thus, the present study provides an excellent bio-adsorbent chitosan nanoparticle generated from fish scales which have potential application as an adsorbent in bioremediation like wastewater treatment.
\end{abstract}

\section{Keywords}

Chitosan Nanoparticle, Fish Scale, Bio Adsorption, Textile Effluents 


\section{Introduction}

Functional bioactive ingredients are known to attract the scientific community, consumers and food manufacturers and there is a steady growth in the scientific evidence supporting the concept of health-promoting ingredients [1] [2].

Chitosan, natural polysaccharide is a partially deacetylated polymer of $\mathrm{N}$-acetyl glucosamine obtained through alkaline deacetylation of chitin [3] [4] [5] [6]. Chitin is found in the exoskeleton of crustaceans and also in fungi and yeast [7] [8].

Apart from this, chitosan is known to have medical, therapeutic, pharmaceutical and biomedical properties and also used in agricultural sector as well [9]-[15]. The attribution of chitosan to the textiles industry is considered multi-functional, both chemically and microbiologically [16]-[22].

The white snapper otherwise called as Macolor Niger is common tropical saltwater fish. Large amounts of scale wastes were discarded post consumption of these species and harmed the environment. Hence, chitin and chitosan can be extracted from the discarded fish scales and thus protect the environment.

This study deals with the preparation of chitosan nanostructures from fish scale wastes and their application as a bio-adsorbent in wastewater treatment from textile industrial effluents.

\section{Material \& Methods}

\subsection{Collection of Fish Scales}

The scales of white snapper were collected from Chennai fish market in. The scales were dried at $50^{\circ} \mathrm{C}$ in an oven for 24 hours. The scales were then crushed and preserved in air tight containers (Figure 1).

\subsection{Deproteination}

It was refined by adding $2 \mathrm{~N} \mathrm{NaOH}$ solution and then stirred and heated at a temperature of $90^{\circ} \mathrm{C}$ for 1 hour. Once separated from the solution, fish scales are washed with distilled water and then dried at $80^{\circ} \mathrm{C}$ for 8 hours.

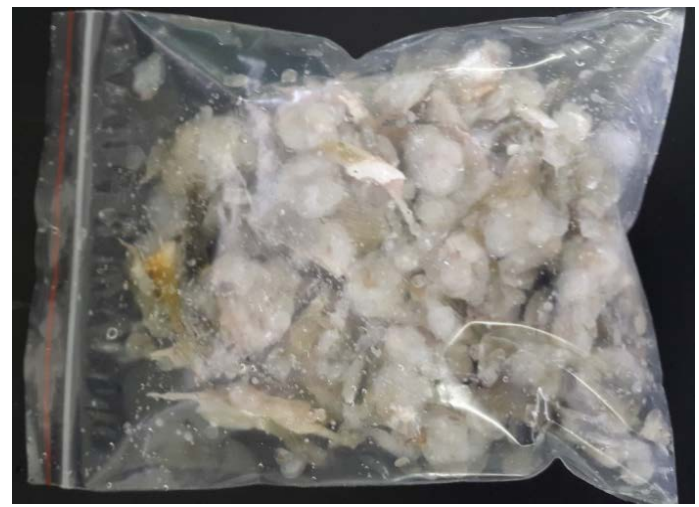

Figure 1. Scales of white snapper. 


\subsection{Demineralization}

Dry solids deproteinase subsequently demineralized by using a solution of $\mathrm{HCl} 1$ $\mathrm{N}$ and stirred at room temperature for 1 hour. Once filtered, the solids are washed with distilled water and then dried at $80^{\circ} \mathrm{C}$ for 8 hours.

\subsection{Deacetylation}

After boiling chitin in $50 \% \mathrm{NaOH}$ solution at $120^{\circ} \mathrm{C}$ for 3 hours, the solid is then washed with distilled water and are dried at $80^{\circ} \mathrm{C}$ for 8 hours. This resultant is called chitosan.

\subsection{Chitosan Nanoparticles}

Chitosan $1 \mathrm{~g}, 15 \mathrm{~mL}$ of $1 \%$ acetic acid and $\mathrm{NH}_{3}(\mathrm{c})$ were mixed and the resulting gel formed is washed with distilled water and is dried at a temperature of $80^{\circ} \mathrm{C}$ for 24 hours.

\subsection{Silver-Loaded Chitosan Nanocomposite}

Silver nanoparticles were obtained by dissolving $\mathrm{AgNO}_{3}$ for about 20 min post which sodium citrate and sodium borohydride solutions were added and mixed. The settled particles were collected by filtration. For the synthesis of C-Ag nanocomposite, $0.5 \mathrm{~g}$ of chitosan, $2 \%$ acetic acid, $1 \%$ PVA solution, $20 \% \mathrm{Na}_{2} \mathrm{SO}_{4}$ solution and $0.1 \mathrm{~g}$ of synthesized silver were added and mixed.

\subsection{Scanning Electronic Microscopy (SEM)}

The features of the nanoparticles were examined by Scanning electron microscope (Model 2360, Leo Oxford, England).

\subsection{Particle Size}

The particle size was observed by Shimadzu SALD-2300.

\subsection{Photo Catalytic Degradation of Dye}

The stock solution was prepared by adding $1000 \mathrm{~mL}$ of double distilled water to $10 \mathrm{mg}$ of Torque blue and Orange dye. A control was also preserved without the addition of silver nanoparticles. The suspension was stirred for half an hour and was kept under sunlight. Aliquots of 2 - $3 \mathrm{ml}$ suspension were sieved and utilized to estimate the photo catalytic degradation of dye (Figure 2). The absorbance spectrum of the supernatant was calculated using UV-Vis spectrophotometer at different wavelength.

\subsection{Percentage of Dye Degradation}

$$
\% \text { Decolourization }=100 \times[(I-F) / I]
$$

where $I$ is the initial concentration of dye solution and $F$ is the final concentration of dye solution after photocatalytic degradation. 


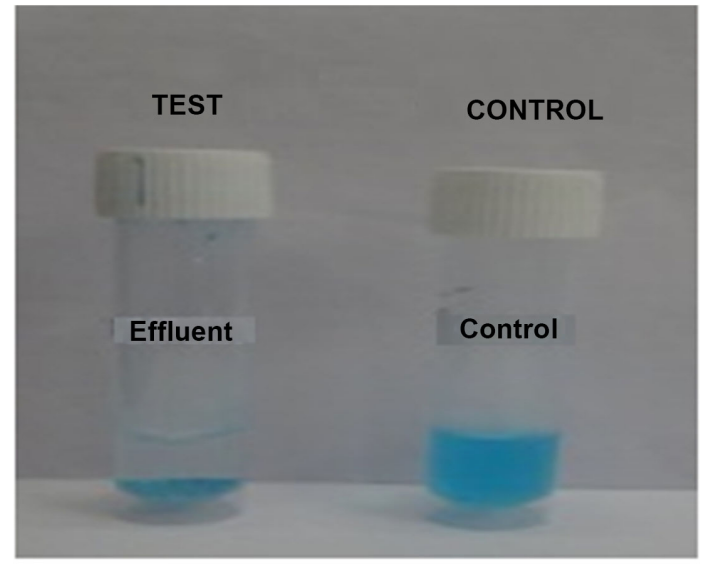

Figure 2. Textile effluents treated with Chitosan $\mathrm{Na}-$ noparticle.

\subsection{Fourier Transform Infrared Spectra (FTIR)}

The chitosan were then categorized in potassium bromide pellets by infrared spectrophotometer.

\subsection{Estimation of Thermodynamic Parameters}

a) Langmuir Isotherm

b) Freundlich Isotherm

$$
\begin{gathered}
\text { Langmuir Isotherm } q e=((C 0-C e) * V) / m \\
\text { Freundlich Isotherm } K F=q m /(C 0) 1 / n
\end{gathered}
$$

where $q e$, amount of solute adsorbed per unit weight of solid at equilibrium $(\mathrm{mg} / \mathrm{g}) ; C$, equilibrium concentration of solute remaining in solution $(\mathrm{mg} / \mathrm{L})$; $\mathrm{qm}$, maximum adsorption capacity for single layer formation; $K F$, Freundlich constant. From among above isotherms an isotherm that is close to the dye removal process must be selected so that further analysis of the adsorption system could be carried out.

\section{Results and Discussion}

Chitosan was extracted from the fish scales from fish stalls of Kanathur by using chemical treatments (Figure 1). The prepared chitosan nanoparticle exhibited, rough, thick and rod shaped surface morphology under electron microscopic examination at 50X magnification (Figure 3(a) \& Figure 3(b)). The silver-loaded chitosan nanocomposite exhibited silver particle embedded, rod shaped morphology under electron microscopic examination at 50X magnification. (Figure 4(a) \& Figure 4(b)).

The particle size of chitosan nanoparticle was around $1.123 \mathrm{~nm}$ (Figure 5). The absorbance spectrum of chitosan nanoparticle was calculated by means of UV-Visible spectrophotometer at the different wavelength (Figure 6(a)-(c)). The time duration for the adsorption of the dye is 2 hours (Figure 7). Langmuir 


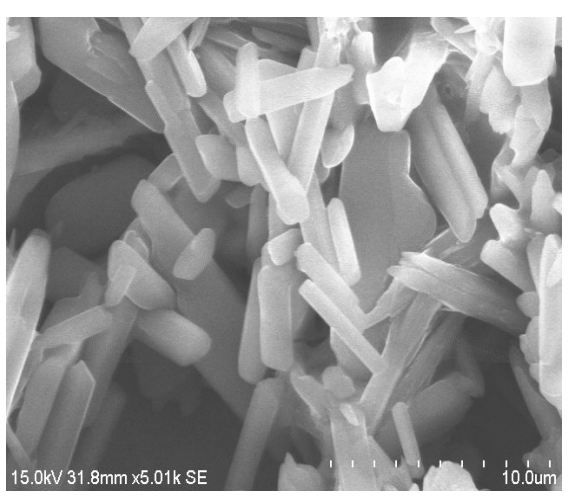

(a)

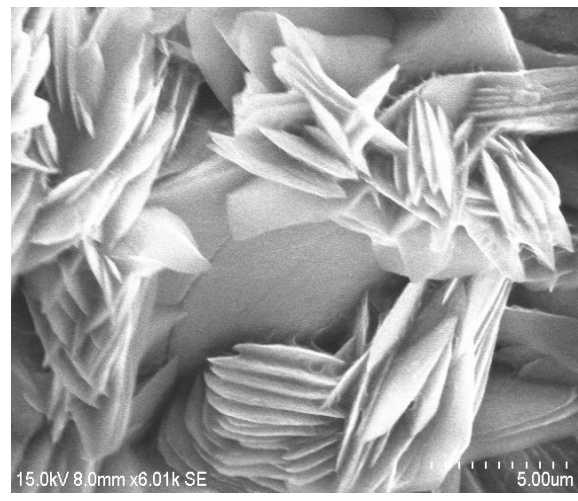

(b)

Figure 3. (a) FESEM photographs of prepared Chitosan nanoparticle; (b) FESEM photograph of Chitosan nanoparticle.

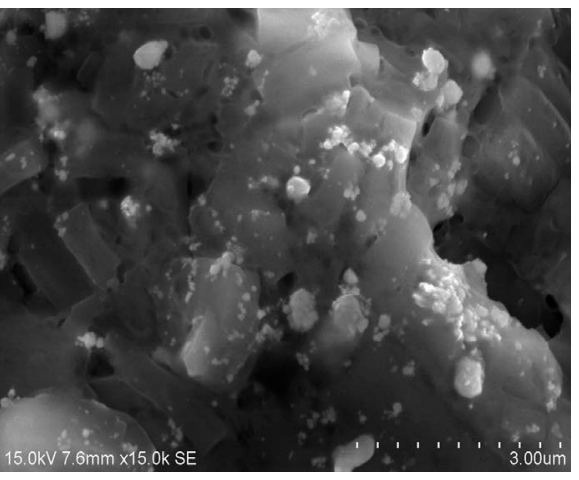

(a)

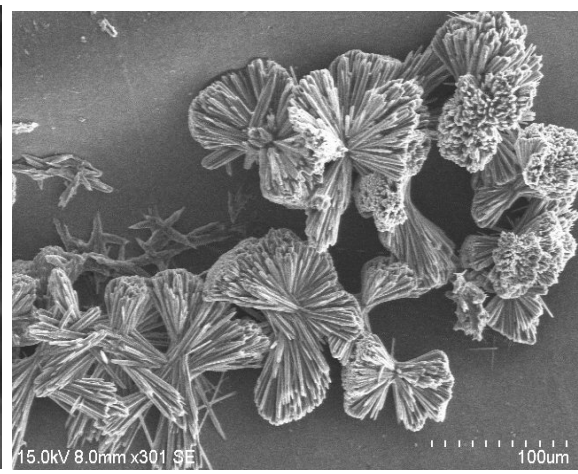

(b)

Figure 4. (a) FESEM photograph of Silver-loaded Chitosan nanocomposite; (b) FESEM photograph of Silver-loaded Chitosan nanocomposite (Rod shaped).

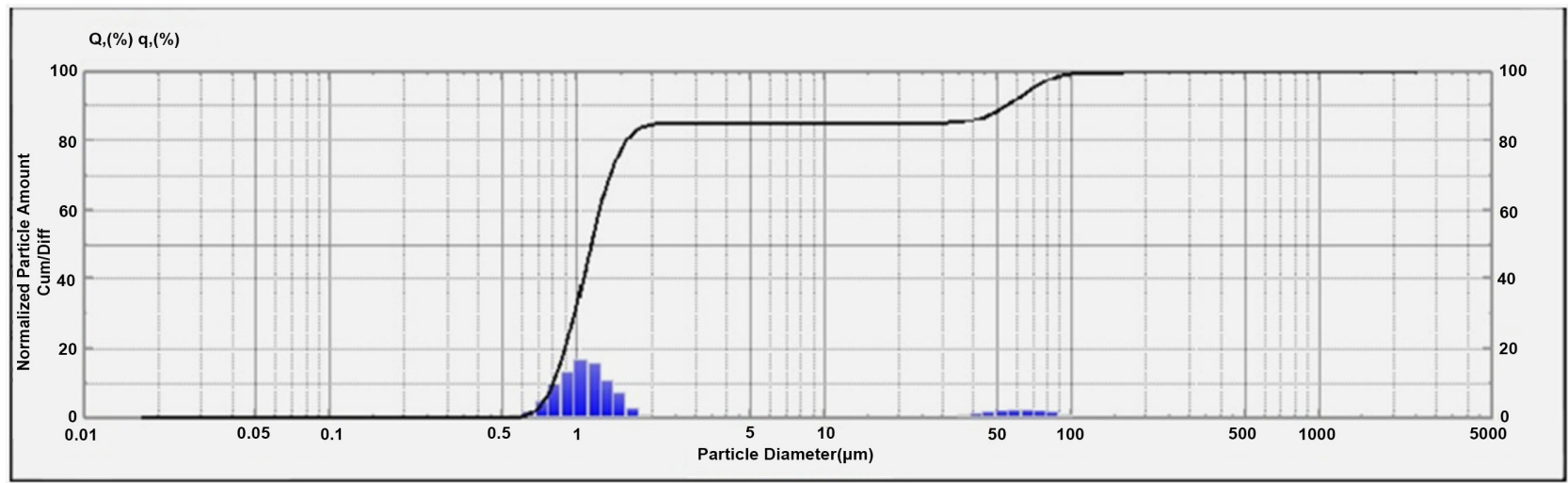

Figure 5. Particle size of Chitosan nanoparticle.

model is considered to be the best the dye removal isotherm model showing a monolayer adsorption, with a correlation coefficient value (R2) of 0.4912 (Figure 8). According to the Langmuir model maximum adsorption capacity for forming single layer. So this study shows that chitosan has a high adsorption capacity that is over $65 \%$ of its weight. 


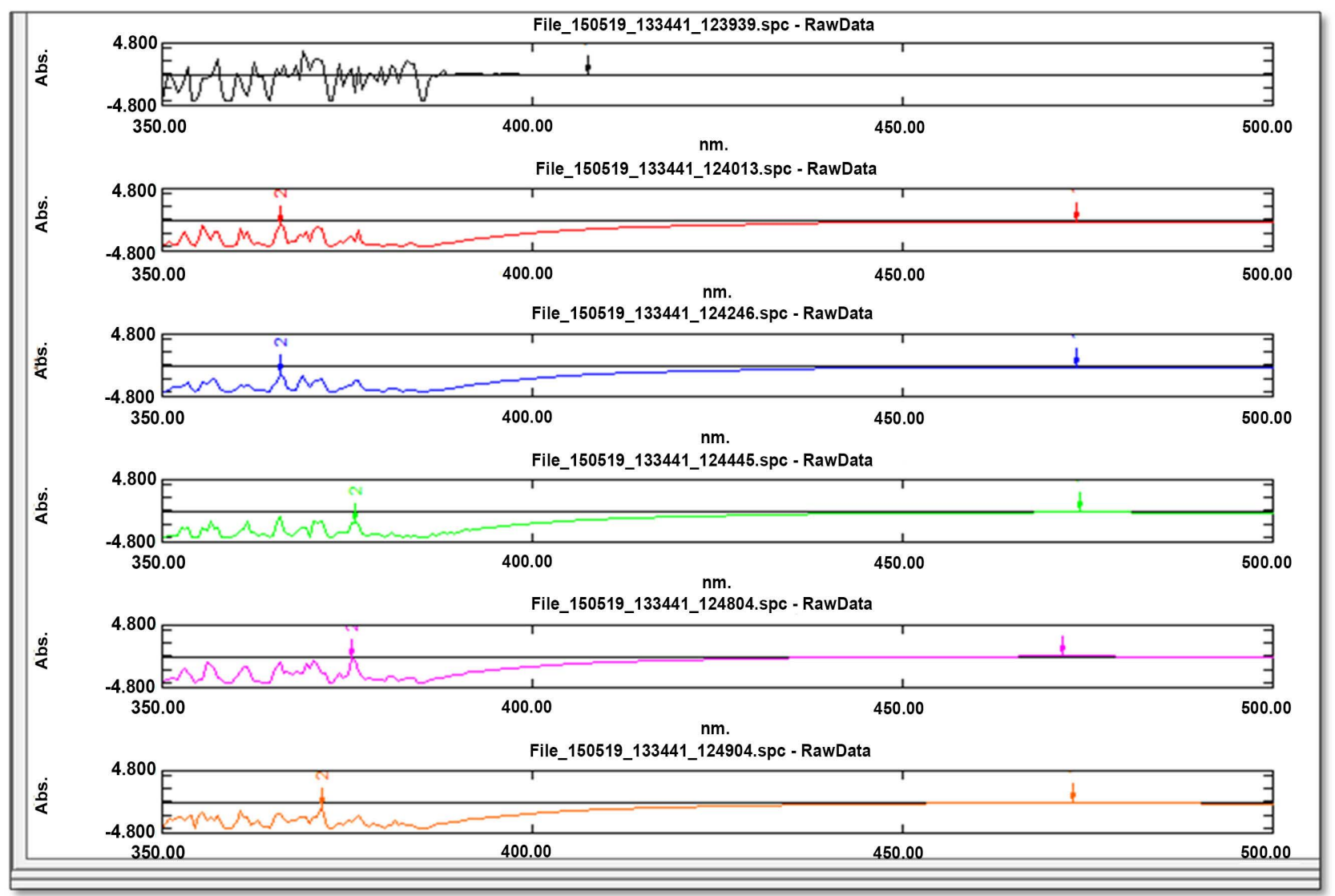

(a)

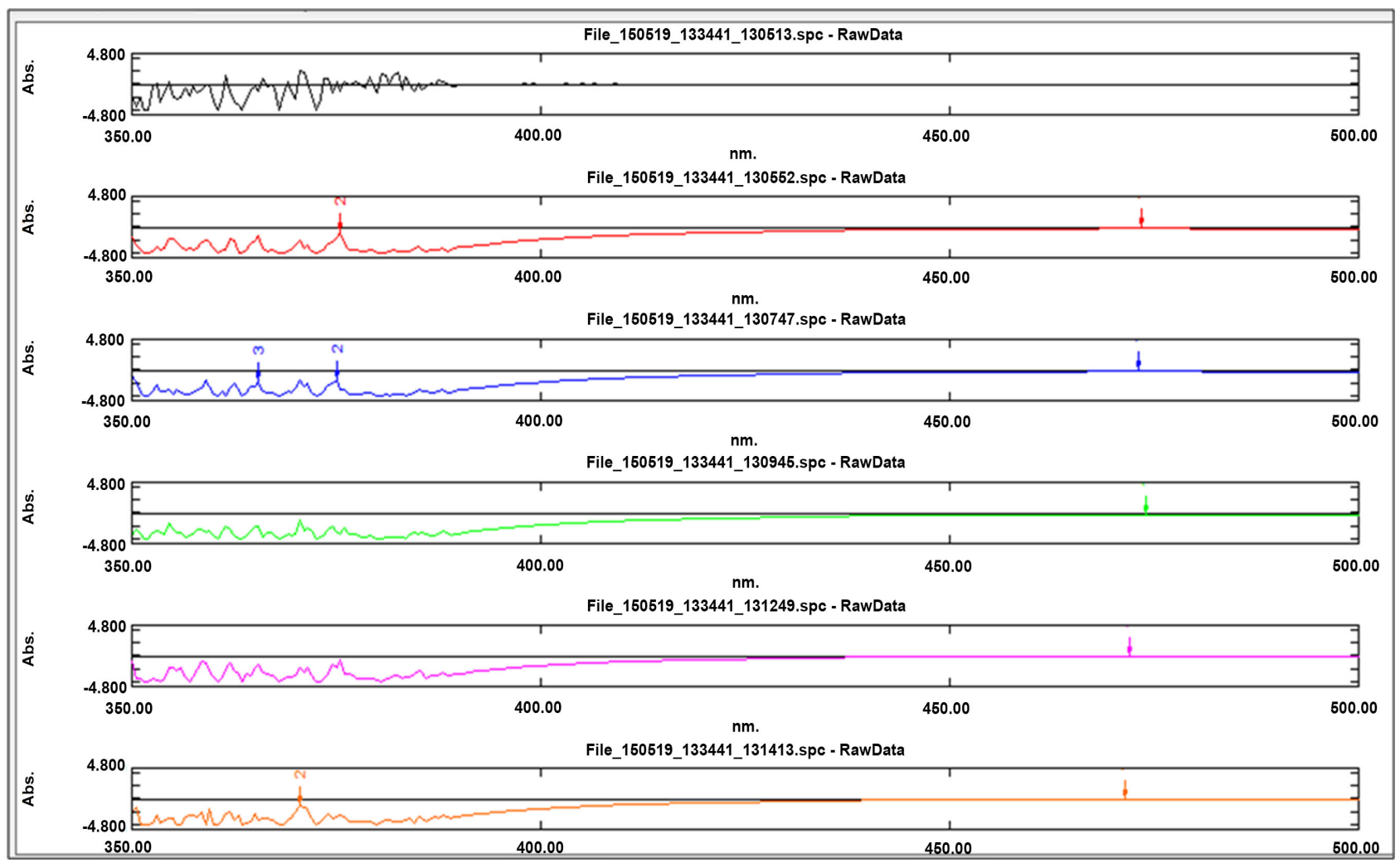

(b) 


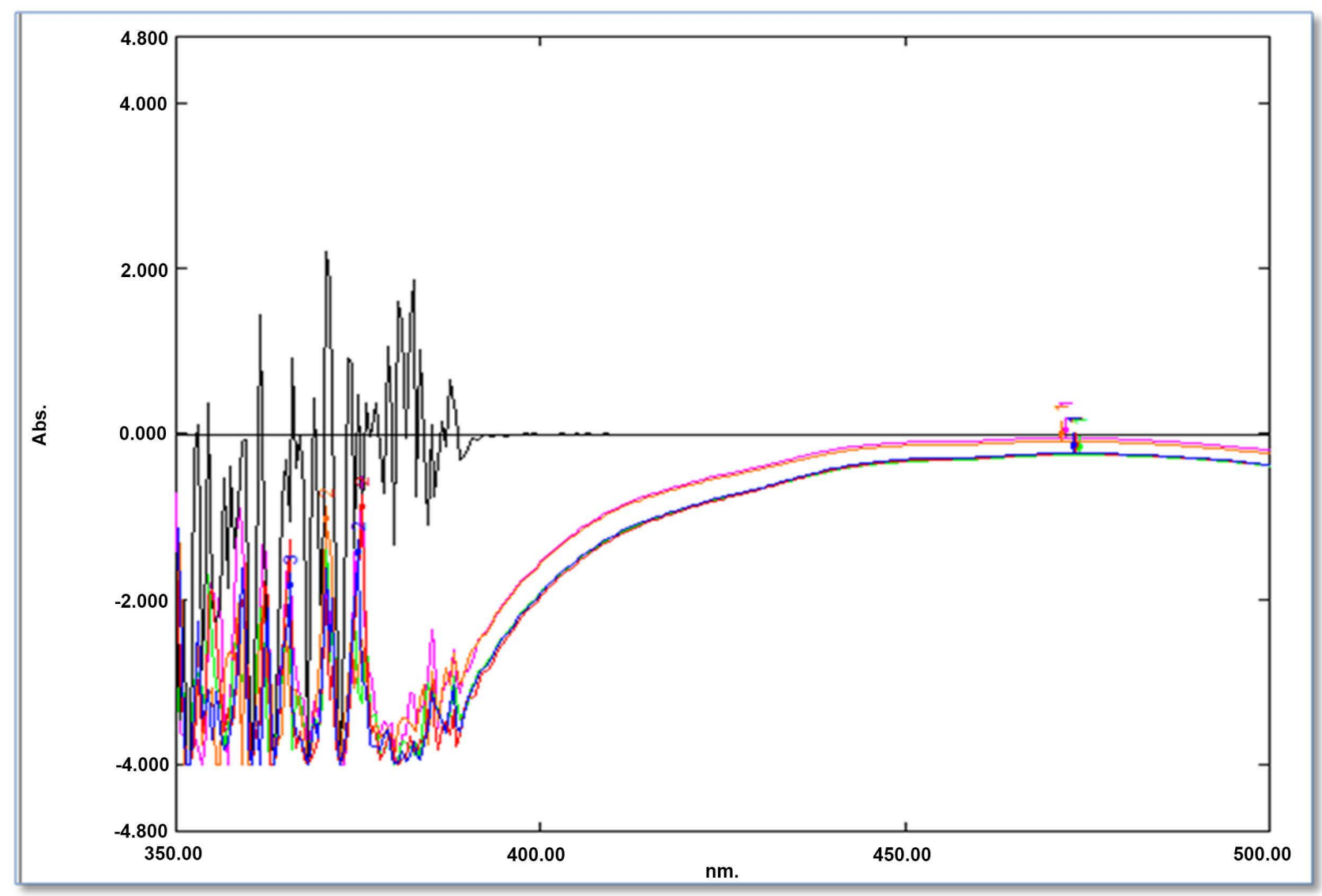

(c)

Figure 6. (a)Visible Spectra of Torque blue G treated Chitosan nanoparticle; (b) Visible Spectra of Orange dye treated Chitosan nanoparticle; (c) Combined Visible Spectra of Chitosan nanoparticle treated with Torque blue G and Orange dye.

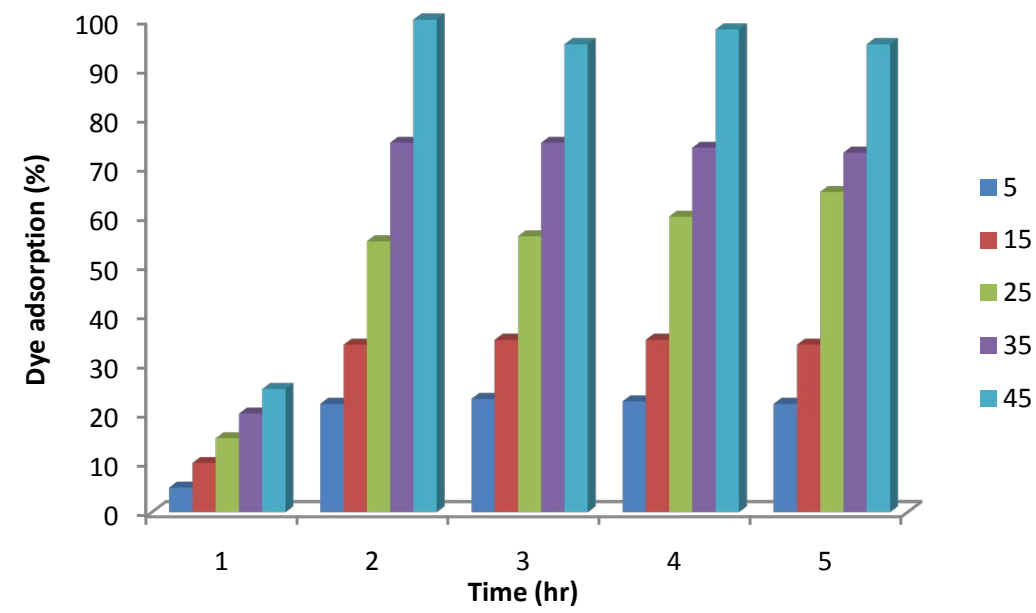

Figure 7. Effect of time duration for the adsorption of the dye.

The absorption bands of FTIR of chitosan were found between 3643 - 3938 $\mathrm{cm}^{-1}$ related to associated in N-H bond primary amines, $700 \mathrm{~cm}^{-1}-3650 \mathrm{~cm}^{-1}$ was associated with $\mathrm{C}-\mathrm{Cl}$ chloride; $\mathrm{C}-\mathrm{H}$ aromatics; $\mathrm{C}-\mathrm{N}$ stretch aliphatic amines; $\mathrm{N}-\mathrm{O}$ asymmetric stretch nitro compounds; $\mathrm{R}-\mathrm{C}(\mathrm{O})-\mathrm{Cl}$ Acyl Chlorides; O-H 


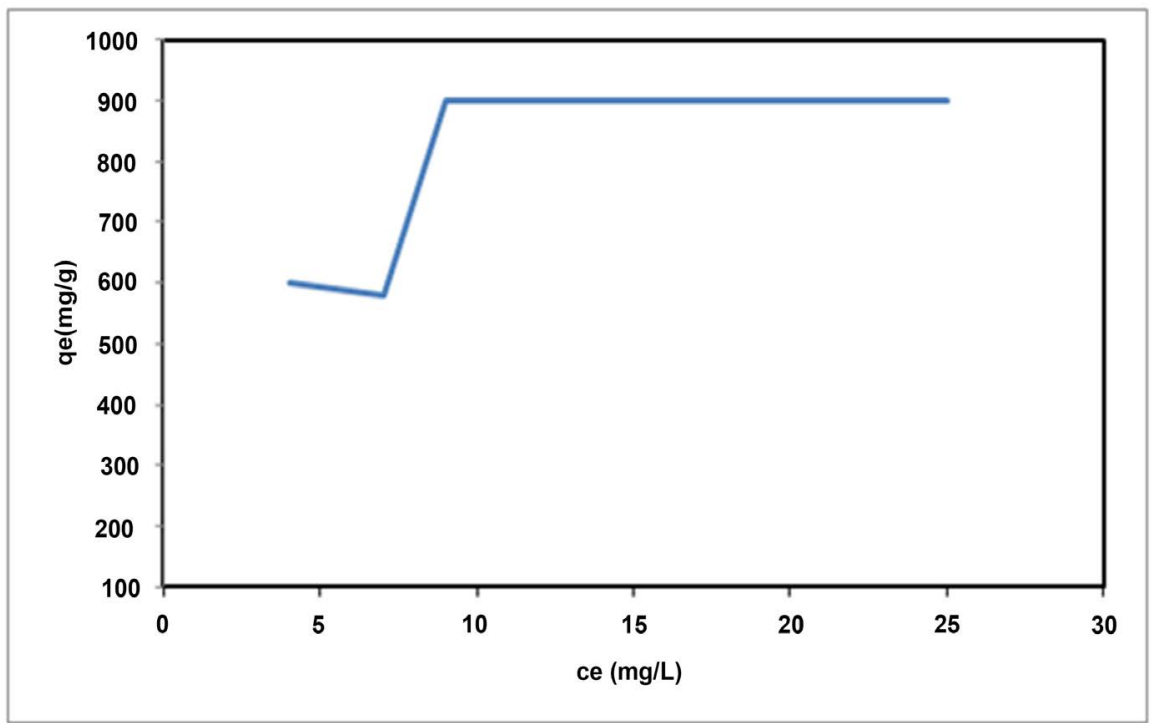

Figure 8. Adsorption isotherm of torque blue $g$ and orange dye by Chitosan Nanoparticle.

Table 1. (a) FT-IR Analysis of Chitosan Nanoparticle; (b) FT-IR Analysis of Torque Blue G treated Chitosan Nanoparticle; (c) FT-IR Analysis of Orange treated Chitosan Nanoparticle.

(a)

\begin{tabular}{ccc}
\hline 712.65 & $\mathrm{C}-\mathrm{Cl}$ & Chloride \\
\hline 858.26 & $\mathrm{C}-\mathrm{H}$ & Aromatics \\
1081.03 & $\mathrm{C}-\mathrm{N}$ stretch & Aliphatic amines \\
1476.41 & $\mathrm{~N}-\mathrm{O}$ asymmetric stretch & Nitro compounds \\
1788.85 & $\mathrm{R}-\mathrm{C}(\mathrm{O})-\mathrm{Cl}$ & Acyl Chlorides \\
2521.75 & O-H stretch & Carboxylic acids \\
2920.03 & C-H stretch & Alkanes \\
3434.98 & O-H stretch & Alcohols \\
3642.32 & O-H stretch & Alcohols \\
\hline
\end{tabular}

(b)

\begin{tabular}{ccc}
\hline 711.68 & C-Cl & Chloride \\
\hline 873.69 & C-H & Aromatic \\
1047.27 & C-N stretch & Aliphatic amines \\
1470.62 & C-H bend & Alkanes \\
1792.71 & R-C(O)-Cl & Acyl Chlorides \\
2515 & O-H stretch & Carboxylic Acids \\
2921.96 & C-H stretch & Alkanes \\
3404.13 & O-H stretch & Alcohols \\
\hline
\end{tabular}


(c)

\begin{tabular}{ccc}
\hline 712.65 & $\mathrm{C}-\mathrm{Cl}$ & Chloride \\
\hline 859.23 & $\mathrm{C}-\mathrm{H}$ & Aromatics \\
1081.99 & $\mathrm{C}-\mathrm{N}$ stretch & Aliphatic amines \\
1475.44 & $\mathrm{~N}-\mathrm{O}$ asymmetric stretch & Nitro compounds \\
1787.89 & $\mathrm{C}=\mathrm{O}$ stretch (R-C $(\mathrm{O})-\mathrm{Cl})$ & Acyl Chlorides \\
2521.75 & O-H stretch & Carboxylic acids \\
2852.52 & C-H stretch & Alkanes \\
2920.99 & C-H stretch & Alkanes \\
3642.32 & O-H stretch & alcohols \\
\hline
\end{tabular}

stretch carboxylic acids; $\mathrm{C}-\mathrm{H}$ stretch alkanes; $\mathrm{O}-\mathrm{H}$ stretch alcohols; $\mathrm{O}-\mathrm{H}$ stretch alcohols (Tables 1(a)-(c)).

\section{Conclusion}

In the current study, the chitosan nanoparticles were geared up from white snapper scales and used in wastewater treatment from textile industries as a bio-adsorbent. It is concluded that chitosan nanoparticles can be used as a potential bio adsorptive filter owing to their positive organic possessions.

\section{Conflicts of Interest}

The authors declare no conflicts of interest regarding the publication of this paper.

\section{References}

[1] Elliott, R. and Ong, T.J. (2002) Science, Medicine, and the Future of Nutritional Genomics. BMJ, 324, 1438-1442. https://doi.org/10.1136/bmj.324.7351.1438

[2] Bell, L.N. (2001) Handbook of Nutraceuticals and Functional Foods. New York, USA.

[3] Sevda, S. and McClureb, S.J. (2004) Potential Applications of Chitosan in Veterinary Medicine. Advanced Drug Delivery Reviews, 56, 1467-1480. https://doi.org/10.1016/j.addr.2004.02.007

[4] Se, K.K. and Niranjan, R. (2005) Enzymatic Production and Biological Activities of Chitosan Oligosaccharides (COS): A Review. Carbohydrate Polymers, 62, 357-368. https://doi.org/10.1016/j.carbpol.2005.08.012

[5] Sunil, A.A., Nadagouda, N.M. and Tejraj, M. (2004) Recent Advances on Chitosan-Based Micro- and Nanoparticles in Drug Delivery. Journal of Controlled Release, 100, 5-28. https://doi.org/10.1016/j.jconrel.2004.08.010

[6] Mincea, M., Negrulescu, A. and Ostafe, V. (2012) Preparation, Modification, and Applications of Chitin Nanowhiskers: A Review. Rev Adv Mater Sci, 30, 225e42.

[7] Illum, L., Jabbal-Gill, I., Hinchcliffe, M., Fisher, A.N. and Davis, S.S. (2001) Chitosan as a Novel Nasal Delivery System for Vaccines. Advanced Drug Delivery Reviews, 51, 81-96. https://doi.org/10.1016/S0169-409X(01)00171-5

[8] Hwang, J.K. and Shin, H.H. (2000) Rheological Properties of Chitosan Solutions. 
Korea-Australia Rheology Journal, 12, $175 \mathrm{e} 9$.

[9] Li, Q., Dunn, E.T. and Grandmaison, E.W. (1997) Applications and Properties of Chitosan. In: Goosen, M.F.A., Ed., Applications of Chitin and Chitosan, Technomic Publishing Co., Lancaster, 3e29.

[10] Nishimura, K., Nishimura, S. and Nishi, N. (1984) Immunological Activity of Chitin and Its Derivatives. Vaccine, 2, 93e9.

[11] Allan, G.G., Altman, L.C., Bensinger, R.E., Ghosh, D.K., Hirabayashi, Y., Neogi, A.N. and Neogi, S. (1984) Biomedical Applications of Chitin and Chitosan. In: Zikakis, J.P., Ed., Chitin, Chitosan and Related Enzymes, Academic Press, New York, 119-133. https://doi.org/10.1016/B978-0-12-780950-2.50013-7

[12] Zhu, C.L., Wang, X.W., Lin, Z.Z., Xie, Z.H. and Wang, X.R. (2014) Cell Microenvironment Stimuli-Responsive Controlled-Release Delivery Systems Based on Mesoporous Silica Nano Particles. Journal of Food and Drug Analysis, 22, 18-28.

[13] Badawy, M.E.I., Rabea, E.I., Rogge, T.M., Stevens, C.V., Smagghe, G., Steurbaut, W. and Hofte, M. (2004) Synthesis and Fungicidal Activity of $€$ new N,O-Acyl Chitosan Derivatives. Biomacromolecules, 5, 589-595.

[14] Balakrishnan, B., Mohanty, M., Umashankar, P.R. and Jayakrishnan, A. (2005) Evaluation of an In Situ Forming Hydrogel Wound Dressing Based on Oxidized Alginate and Gelatin. Biomaterials, 26, 6335-6342.

[15] Howling, G.I., Dettmar, P.W., Goddard, P.A., Hampson, F.C., Dornish, M. and Wood, E.J. (2001) The Effect of Chitin and Chitosan on the Proliferation of Human Skin Fibroblasts and Keratinocytes in Vitro. Biomaterials, 22, 2959-2966.

[16] Bandyopadhyay, B.N., Seth, G.N. and Moni, M.M. (2001) Application of Chitosan Indyeing and Finishing. Bombay Textile Research Association Scan, 1, 5-12.

[17] Sang-Hoon, L. and Samuel, M.H. (2003) Review of Chitosan and Its Derivatives as Antimicrobial Agents and Their Uses as Textile Chemicals. Journal of Macromolecular Science, Part C Polymer Reviews, 43, 223-269.

[18] Seungsin, L., Jeong-Sook, C. and Gilsoo, C. (1999) Antimicrobial and Blood Repel Lentfinishes for Cotton and Nonwoven Fabrics Based on Chitosan and Fluoropolymers. Textile Research Journal, 69, 104-112. https://doi.org/10.1177/004051759906900205

[19] Li, Q., Dunn, E.T., Grandmaison, E.W. and Goosen, M.F.A. (1992) Applications and Properties of Chitosan. Journal of Bioactive and Compatible Polymers, 7, 370-397.

[20] Ravi Kumar, M.N.V. (2000) A Review of Chitin and Chitosan Applications. Reactive and Functional Polymers, 46, 1-27.

[21] Wang, X.H., Cui, F.Z. and Zhang, Y.H. (2003) Preparation and Characterization of Colla Gen/Chitosan Matrices as Potential Biomaterials. Journal of Bioactive and Compatible Polymers, 18, 453-467.

[22] Piccin J.S., Vieira, M.L.G., Gonçalves J.O., Dotto G.L. and Pinto, L.A.A. (2009) Adsorption of FD \& C Red No. 40 by Chitosan: Isotherms Analysis. Journal of Food Engineering, 95, 16-20. 